\title{
LA SIERRA TARAHUMARA, SIN JUSTICIA AMBIENTAL*
}

\section{THE SIERRA TARAHUMARA, A CASE ABOUT ENVARIOMENTAL JUSTICE}

\section{Emilio CRUZ SÁNCHEZ \\ Carlos Eduardo DeLGado RiverA**}

RESUMEN: En los Estados contemporáneos es necesario que la sociedad tenga las herramientas adecuadas para involucrarse en el cuidado de los recursos naturales. En México se cuenta con la "denuncia popular", y los autores hacen un análisis para determinar si es una herramienta efectiva para involucrar a los gobernados en el cuidado de los recursos naturales o no, considerando que con la denuncia popular la sociedad en su conjunto puede evidenciar los excesos y delitos que están cometiendo al ambiente tanto particulares como el propio Estado. Para ello, se basan en la información recopilada en un expediente de hechos que se integró ante la Comisión de Cooperación Ambiental (CCA), sobre tres casos relacionados con tala ilegal en la sierra tarahumara. Dicho informe se integró debido a la denuncia de organizaciones de la sociedad civil, en las que señalan que el Estado mexicano no está cumpliendo con su normatividad en materia ambiental. La exigencia de la ciudadanía por autoridades que cumplan con sus mandatos legales no tiene el eco suficiente, y eso pone en riesgo su derecho a
ABSTRACT: In contemporary States, it is necessary to ensure that society has the right legal tools to be involved in the care of natural resources. In Mexico, the "denuncia popular" (popular denunciation) is the legal figure to do so. Therefore, the purpose of this article is to determine if it "popular denunciation" is an effective tool to involve the civil society in the care of natural resources, by considering that society as a whole can denounce and evidence the crimes committed by individuals, or even the State itself, to the environment. This article is based on information gathered from legal cases litigated before the Commission for Environmental Cooperation (CEC) about three cases related to illegal logging in the Sierra Tarahumara that were denounced by civil society organizations arguing that the Mexican State is not complying its own environmental normativity. The authors reflect that the civil society requirement that the State complies its legal mandates, does not have enough echo, which puts at risk their right to have a healthy environment. Therefore, the authors offer a brief analysis of the actions of the Federal Attorney for Environmental Protection (Profepa) by considering the legal figure of the "po pular denunciation", in order to present a series of recommendations. In summary, this article revieweshe (in)effectiveness of

* Artículo recibido el 2 de octubre de 2017 y aceptado para su publicación el 3 de noviembre de 2017.

** Egresados de la especialidad de derecho ambiental, del Posgrado de la Facultad de Derecho de la UNAM.

Boletín Mexicano de Derecho Comparado, nueva serie, año L, núm. 151, enero-abril de 2018, pp. 85-106. 
contar con un medio ambiente sano. Los autores aprovechan el tema de la denuncia popular para hacer un somero análisis del actuar de la Procuraduría Federal de Protección al Ambiente y dejar algunas conclusiones, que bien se podrían tomar como recomendaciones. Por lo que este texto presenta un estudio de la (in)efectividad de la denuncia popular como un instrumento jurídico a disposición de las personas, para asegurarse de que el Estado cumpla con su responsabilidad de garantizar un ambiente sano a sus gobernados

Palabras clave: Instrumentos jurídicos, protección ambiental, justicia ambiental. the t"popular denunciation" as a legal tool available to people, to ensure that the State fulfills its responsibility to ensure a healthy environment for the society, as a whole.

Keywords: Regulation, environmental protection, environmental justice.

SUMARIO: I. Introducción. II. Antecedentes: el TLCAN, el ACAANy la Comisión en México. III. La denuncia popular y el caso de la sierra tarahumara. IV. México y el expediente de hechos final. V. Consideraciones finales. VI. Bibliografia.

\section{INTRODUCGIÓN}

Estamos en un momento histórico en el que es indispensable hablar de protección ambiental. La relación armónica que podamos sostener con nuestro entorno es básica para proteger nuestra propia existencia, y difícilmente las alteraciones que le hacemos a la naturaleza harán que se extinga la vida en el planeta, pero sí pueden poner en riesgo peligrosamente nuestra permanencia como raza humana en la Tierra.

Esto exige que los instrumentos para cuidar y asegurar los recursos naturales deben ser más eficientes e impulsar la participación activa de la sociedad, buscando que el cuidado del ambiente sea responsabilidad de todas las personas que habitamos en este mundo.

El derecho ambiental proporciona una serie de herramientas que la sociedad puede usar para mejorar el entorno en el que vive, pero para que éstas funcionen es indispensable que las autoridades respondan eficazmente cuando las personas buscan involucrarse y asumir la responsabilidad compartida de cuidar el ambiente.

Esta obra está bajo una Licencia Creative Commons

Atribución-NoComercial-SinDerivar 4.0 Internacional, IIJ-UNAM.

Boletín Mexicano de Derecho Comparado, núm. 151, pp. 85-106. 
En la medida en que los seres humanos nos interesemos y preocupemos más por nuestro entorno y los seres vivos con los que convive nuestra especie, las instituciones jurídicas diseñadas para proteger el ambiente serán cada vez más efectivas.

Este trabajo analiza la denuncia popular, ya que es una de las herramientas que el derecho pone a disposición de las personas, de las organizaciones sociales, de las comunidades, para que puedan denunciar daños al ambiente, y se active la arquitectura institucional del gobierno para la protección de los recursos naturales.

Vamos a presentar el caso de tres comunidades indígenas que viven en la sierra tarahumara, y cómo quisieron utilizar esta herramienta, para intentar proteger los recursos naturales de su territorio, y cuál fue la respuesta que obtuvieron de las autoridades.

El objetivo de este trabajo es analizar cuál es la efectividad de la denuncia popular, con el fin de exponer elementos que permitan deducir si este instrumento es adecuado para que la sociedad se involucre en el cuidado del ambiente y garantizar el acceso a la justicia ambiental; esto, contrastado con los acontecimientos que expone la Comisión de Cooperación Ambiental (CCA) en el expediente de hechos de la sierra tarahumara.

Lo sucedido en la sierra tarahumara es relevante, justo porque trascendió a una figura multilateral y evidenció a México en el ámbito internacional; por eso iniciamos con una breve explicación de por qué los países firmantes del Tratado del Libre Comercio de América del Norte (TLCAN) deciden crear una figura como la CGA; después explicamos la figura de la denuncia popular, y cómo funcionó en el caso de la sierra tarahumara. Ya perfilando el final del texto dedicamos un apartado sobre la resolución del expediente de hechos, con el fin de exponer las conclusiones a las que llegó la CCA, y en las consideraciones finales exponemos algunas reflexiones sobre la figura de la denuncia popular y el caso presentado ante la CGA.

\section{ANTEGEDENTES: EL TLCAN, EL ACAAN y LA COMISIÓN EN MÉXICO}

En el marco de negociación del Tratado de Libre Comercio de América del Norte (TLCAN), celebrado entre México, Estados Unidos y Canadá, surgen 
un par de instrumentos paralelos al tratado, a saber: el Acuerdo de Cooperación Ambiental de América del Norte (ACAAN) y el Acuerdo de Cooperación Laboral de América del Norte (ACLAN). ${ }^{1}$

En las primeras pláticas de negociación comercial entre los tres países, el tema ambiental era considerado "tema paralelo" con implicaciones para la negociación del Tratado de Libre Comercio. Gracias al reconocimiento, se daba cuenta de la inserción de la materia ambiental en temas económicos (comerciales) y sociales, que en su conjunto conforman la visión del desarrollo sustentable. ${ }^{2}$

Entre los antecedentes internacionales más relevantes que dieron importancia al tema ambiental para ser considerado en el marco de negociación del TLCAN fueron, entre otros, la Conferencia de las Naciones Unidas sobre el Medio Ambiente y el Desarrollo, celebrada en Río de Janeiro en 1992, fuertemente influenciada por la Declaración de Estocolmo de 1972.

En dicha conferencia, México, Canadá y Estados Unidos asumieron las recomendaciones contenidas en la Agenda XXI, que en términos generales es un acuerdo de las Naciones Unidas (ONU) para promover el desarrollo sostenible, a través de acciones a nivel mundial, nacional, local, y, para el caso del Tratado, podría decirse a nivel regional.

Otro factor importante para el caso mexicano sucede en mayo de 1994, cuando México se adhiere a la Organización para la Cooperación y el Desarrollo Económicos (OCDE), vinculandose plenamente a las recomendaciones que el Comité Ambiental de la organización elaboró en 1972, entre ellos el principio "contaminador pagador", y la recomendación de incorporar instrumentos económicos de política ambiental en su normatividad.

Sin duda estos acontecimientos históricos dieron pauta a la consideración del medio ambiente dentro del TLCAN.

Además, la presión que algunas organizaciones sociales (ambientalistas) de Estados Unidos hacían sobre el recién electo presidente Clinton, que con el fin de mostrar un rostro ambientalista y su capacidad de es-

\footnotetext{
$1 \quad$ Publicado en el Diario Oficial de la Federación el 20 de diciembre de 1993.

2 Carmona Lara, María del Carmen, "El Tratado de Libre Comercio y el ambiente (acuerdos paralelos)", en Witker, Jorge (coord.), El tratado de Libre Comercio de América del Norte. Análisis, diagnóstico y propuestas jurídicas, México, UNAM, Instituto de Investigaciones Jurídicas, 1993, t. II, p. 202.
} 
cuchar las demandas sociales, puso como prerrequisitos la firma de dos acuerdos paralelos, para que el Senado pudiera aprobar el TLGAN. ${ }^{3}$

Empero, ¿cómo se insertó el tema ambiental en las negociaciones del Tratado? Sin duda alguna, el eje central del Tratado en principio era primordialmente de carácter comercial, pero en la medida en que se trató de poner precio y costo a los daños que se pudieran generar al medio ambiente, fue necesaria la reconsideración de un acuerdo ambiental.

Derivado de la consideración "comercial" del medio ambiente, en la negociación del TLCAN aparecieron las siguientes preguntas: ¿cómo puede evitarse que los países utilicen medidas ambientales como un disfraz para poner barreras al comercio?, más aún ¿cómo pueden hacerse cumplir los convenios internacionales relacionados con el medio ambiente?, la soberanía de los Estados en relación con sus recursos naturales ¿les da el derecho a dañar el medio ambiente? Y la única solución era considerar la importancia del tema ambiental y la posible realización de un acuerdo paralelo referente al medio ambiente. ${ }^{4}$

El TLCAN, junto con sus acuerdos paralelos - ambiental y laboral-, entró en vigor el primero de enero de 1994, como instrumento de integración comercial entre los tres países. ${ }^{5}$ Son diversos los objetivos del TLCAN, pero en materia ambiental, el Tratado en su preámbulo establece que los objetivos comerciales y de integración deben ser emprendidos congruentemente con la protección y conservación del medio ambiente, y en todo momento promoviendo el desarrollo sustentable, así como el reforzamiento de la elaboración y aplicación de leyes y reglamentos en materia ambiental, lo que implica el reconocimiento de cada país para elaborar y crear normas más convenientes en cuanto a la protección de la vida, la salud, y el ambiente, con el compromiso de no reducir sus medidas de protección ambiental con el fin de atraer mayor inversión de capitales.

Es por ello que el ACAAN, en virtud de alcanzar un desarrollo sustentable en la región, creó la Comisión para la Cooperación Ambiental,

3 Studer, Isabel, Comercio, medio ambiente y asuntos laborales. Hacia un modelo de cooperación en America del Norte, consultado el 25 de junio de 2014 en biblio.juridicas.unam.mx/libros/6/2904/13.pdf.

4 Carmona Lara, María del Carmen, op. cit., p. 296.

5 Witker Velásquez, Jorge Alberto, Derecho del comercio exterior, México, UNAM, Instituto de Investigaciones Jurídicas-Asociación de Agentes Aduanales del Aeropuerto de México, A. C., 2011, p. 190. 
para resolver controversias entre personas u organizaciones no gubernamentales y los Estados. La Comisión resuelve los asuntos sometidos ante ella respetando en todo momento los principios de derecho internacional ambiental, entre ellos el principio de prevención ambiental, ${ }^{6}$ el principio de soberanía de los Estados sobre sus recursos naturales, ${ }^{7}$ el principio de cooperación internacional para la protección ambiental. ${ }^{8}$

En conjunto, los principios obligan a los Estados a impedir el daño ambiental en ejercicio de su soberanía; es decir, respetaran los vínculos sociales, económicos y ambientales tomando en cuenta las diferencias existentes entre las riquezas naturales, sus capacidades tecnológicas y de infraestructura de cada uno, porque los impactos generados al ambiente en algunas ocasiones no conocen fronteras y pueden afectar a otros Estados.

\section{La CCA y el caso de la sierra tarahumara}

La Comisión, en apego a sus funciones, ${ }^{9}$ recibió el 9 de junio de 2000, la petición formulada por la Comisión de Solidaridad y Defensa de los Derechos Humanos, Asociación Civil (en adelante COSYDDHAC), una organización mexicana con trabajo en la sierra.

La asociación civil denunciaba el incumplimiento de las autoridades mexicanas respecto a la aplicación adecuada de la legislación ambiental,

6 Señala César Nava: "Este principio se basa en la idea de la diligencia debida, el uso equitativo de los recursos naturales, la buena fe y en general la buena vecindad. Lo que se busca es que se lleven acciones para evitar que ocurra un daño ambiental". En Nava Escudero, César, Estudios ambientales, 2a. ed., México, UNAM, Instituto de Investigaciones Jurídicas, 2011, p. 137.

7 Precisa César Nava, "Este principio conlleva la idea de que así como los Estados tienen el derecho soberano de aprovechar sus recursos, el ejercicio de este derecho no deberá dañar el ambiente (ni de otros Estados ni de zona fuera de su jurisdicción nacional). Este principio ha sido considerado como la base del derecho internacional ambiental". Idem.

8 Para César Nava: "Se traduce en dos deberes. Primero, el deber general de concluir (aunque la obligatio negotiandi no supone una paralela obligatio concluendi) o implementar los objetivos de los tratados u otros instrumentos internacionales. Segundo, el deber específico de intercambiar información, notificación, consulta y participación en la toma de ciertas decisiones, de otorgar asistencia en casos de emergencia, promover investigación científica y tecnológica, elaborar programas de evaluación de impacto ambiental, etcétera". Idem.

9 Acuerdo de Cooperación Ambiental de América del Norte, disponible en: http:// wrere.cec.org/Page.asp?PageID=1226ESiteNodeID=567\&AA_SiteLanguageID=3.

Esta obra está bajo una Licencia Creative Commons

Atribución-NoComercial-SinDerivar 4.0 Internacional, IIJ-UNAM.

Boletín Mexicano de Derecho Comparado, núm. 151, pp. 85-106. 
en particular a lo que se refiere a la denuncia popular y los delitos ambientales del Código Penal Federal en relación con la tala ilegal y otras actividades de extracción de recursos presuntamente ocurridas en varias comunidades indígenas de las montañas de la sierra tarahumara, en el oeste del estado de Chihuahua, a fines de la década de 1990 y 2000.

En el expediente de hechos, ${ }^{10}$ "la peticionaria alega irregularidades en la atención y trámite de denuncias populares presentadas por comunidades indígenas de la Sierra Tarahumara y asevera que tales irregularidades corresponden a una denegación de justicia ambiental". ${ }^{11}$

El Secretariado comenzó a revisar la petición, conforme a los criterios del artículo 14.1 del ACAAN, el 30 de abril de 2001; no obstante, no fue hasta el 6 de noviembre del mismo año cuando el Secretariado determinó el cumplimiento de la petición conforme a los criterios del artículo 14.1, y solicitó una respuesta de la parte gubernamental (artículo 14.2).

Transcurrido un plazo de tres meses, el 15 de febrero de 2002 el Estado mexicano emitió su respuesta, dando pauta al Secretariado con base en la información proporcionada a considerar recomendar abrir el expediente de hechos.

Fue así como el 29 de agosto del mismo año, el Secretariado informó al Consejo, que consideraba la preparación de un expediente de hechos ${ }^{12}$ (artículo 15, ACAAN). Pasado un lapso de seis meses, el 22 de abril de 2003 el Consejo votó instruir al Secretariado a elaborar un expediente de hechos, y que se allegara de la información técnica, científica y jurídica necesaria.

10 Sobre la integración del expediente de hechos, el artículo 15, numerales 1 y 2, del Acuerdo de Cooperación Ambiental de América del Norte, señala que:

"1. Cuando considere que, a la luz de la respuesta dada por la Parte, la petición amerita que se elabore un expediente de hechos, el Secretariado lo informará al Consejo e indicará sus razones.

2. El Secretariado elaborará el expediente de hechos, si el Consejo le ordena hacerlo mediante el voto de dos terceras partes de sus miembros".

11 Expediente de hechos, p. 8.

12 En el expediente de hechos, "el Secretariado presenta los hechos relevantes acerca de si México está incumpliendo o no con la aplicación efectiva de las disposiciones de su Ley General del Equilibrio Ecológico y la Protección al Ambiente (LGEEPA) en lo que respecta al procedimiento de las denuncias populares (artículos 189, 190-93 y 199 de la LGEEPA), así como a los artículos 416, 418 y 419 del Código Penal Federal (CPF) (y los artículos 169 y 202 de la LGEEPA relacionados) en lo concerniente a la participación y persecución de probables delitos ambientales en los casos materia de la petición para los que el Secretariado recomendó elaborar un expediente de hechos", Expediente de hechos, p. 7. 
Consiguiente a la información recabada y analizada, el 6 de abril de 2005 el Secretariado presentó ante el Consejo un proyecto de expediente de hechos, con un periodo de comentarios de 45 días (artículo 15.5, ACAAN), en donde únicamente se recibieron comentarios de Estados Unidos y México.

El 26 de julio de 2005, el Secretariado presentó ante el Consejo el expediente de hechos final para que éste votara hacerlo público o no. El Consejo decidió que fuera público, y el 9 de enero de 2006 se dio a conocer a la ciudadanía. ${ }^{13}$

\section{LA DENUNCIA POPULAR Y EL GASO DE LA SIERRA TARAHUMARA}

De la obligación del Estado mexicano a la protección del ambiente y el reconocimiento a la participación pública, surge como herramienta de política ambiental la denuncia popular. Se trata de un mecanismo de defensa tanto de particulares como de individuos colectivos (asociaciones, sociedades, ONG, etcétera) para exigir al Estado el cumplimiento a un ambiente sano. ${ }^{14}$

El reconocimiento que el sistema jurídico hizo al derecho a un medio ambiente sano implicó un cambio de paradigma de la interdependencia e indivisibilidad ${ }^{15}$ de los derechos. Esto refleja la idea de que la satisfacción de algunos derechos (derecho a la vida) depende de la existencia de otros (derecho a un ambiente sano).

13 Expediente de Hechos, Final Petición Ciudadana Tarahumara (SEM-00-006), Elaborado de conformidad con el artículo 15 del Acuerdo de Cooperación Ambiental de América del Norte. Fecha de consulta: 18/06/2014, disponible en: http://www3.cec.org/is landora/en/item/2750-north-american-environmental-law-and-policy-volume-20-es.pdf.

14 El Estado mexicano ha recogido ese derecho y adoptado en su artículo 4o., párrafo quinto, constitucional, de la siguiente manera: "Toda persona tiene derecho a un medio ambiente sano para su desarrollo y bienestar. El Estado garantizará el respeto a este derecho. El daño y deterioro ambiental generará responsabilidad para quien lo provoque en términos de lo dispuesto por la ley" (D.O.F. 8/02/2012). Cabe señalar que antes de la reforma de 2012, la palabra utilizada para el reconocimiento del derecho era "medio ambiente adecuado" (D.O.F. 28/06/1999). Algunas consideraciones al cambio de la voz "adecuado" a "sano" hacen ver el carácter antropocéntrico y restrictivo de la reforma, limitando, aún, el derecho al medio ambiente únicamente a las personas.

15 Pisarello, Gerardo, Los derechos sociales y sus garantías. Elementos para una reconstrucción, Madrid, Trotta, 2007.

Esta obra está bajo una Licencia Creative Commons

Atribución-NoComercial-SinDerivar 4.0 Internacional, IIJ-UNAM.

Boletín Mexicano de Derecho Comparado, núm. 151, pp. 85-106. 
Así, para poder contar con salud es necesario que exista un ambiente adecuado de la misma forma, el derecho a la vivienda digna se satisface con el derecho a un entorno saludable, y qué decir de la relación entre el derecho humano al agua con la de un ambiente sano. De lo anterior se manifiesta el carácter de interdependencia y conexidad de los derechos.

Considerando que el fundamento de los derechos humanos se encuentra en el principio de dignidad humana, ${ }^{16}$ la cual necesita de una estrecha relación armónica con el entorno (ambiente), y en donde el cumplimiento y eficacia de los derechos sólo es posible con el esfuerzo conjunto del Estado y la sociedad.

La interdependencia e indivisibilidad de los derechos humanos ${ }^{17}$ exige el diseño de políticas que aseguren el cumplimiento y eficacia de los derechos por parte del Estado, sobre todo cuando se vincula el derecho al medio ambiente sano y el de acceso a la justicia; ${ }^{18}$ esto será más fácil en la medida en que se trabaje en conjunto con la sociedad y se promuevan acciones conjuntas: por ejemplo, un adecuado uso de la denuncia popular.

Es entonces que el acceso a la justicia es la vía por la cual las personas del país acuden ante los órganos jurisdiccionales para hacer valer sus derechos en materia de protección del medio ambiente. ${ }^{19}$ No obstante,

16 Herrera Flores, Joaquín. La reinvención de los derechos humanos, Andalucía, Atrapasueños, 2008, pp. 22-24.

17 Vasak, Karel, "La larga lucha por los derechos humanos", El Correo de la UNESCO, noviembre de 1977, pp. 29-32, y Gros Espiell, Héctor, "El derecho al desarrollo como un derecho de la persona humana", Revista de Estudios Internacionales, Madrid, Centro de Estudios Constitucionales, vol. I, núm. 1, enero-marzo de 1980, p. 47.

18 Concordamos con Sergio Eduardo Herrera Torres en que es difícil obtener una definición de justicia ambiental; pero a manera simple se podría decir que es "la posibilidad de obtener una solución jurídica pronta y expedita en un conflicto de naturaleza ambiental". Herrera Torres, Sergio Eduardo, "Acceso a la justicia ambiental", en Carmona Lara, María del Carmen et al., 20 años de procuración de justicia ambiental en México. Un homenaje a la creación de la Procuraduría Federal de Protección al Ambiente, México, UNAM, Instituto de Investigaciones Jurídicas, 2012, p. 110.

19 Ponce Nava, Diana Lucero, "Procuración y acceso a la justicia ambiental y territorial en México", en Ordóñez Cifuentes, José Emilio Rolando y Anglés Hernández, Marisol, Primera Memoria del Seminario Itinerante Internacional "La cuestión agraria: tierras, territorios, medio ambiente, recursos naturales, migrantes, derechos sociales y colectivos de los pueblos", México, UNAM, Instituto de Investigaciones Jurídicas, 2012, p. 111.

Esta obra está bajo una Licencia Creative Commons Atribución-NoComercial-SinDerivar 4.0 Internacional, IIJ-UNAM. Boletín Mexicano de Derecho Comparado, núm. 151, pp. 85-106. 
en el presente caso, como veremos, el acceso a la justicia ambiental manifestó diversos problemas y obstáculos para ser garantizado.

Hay que tener en cuenta que en el caso que nos ocupa, la denuncia popular es una forma de exigir justicia en favor del medio ambiente; en la denuncia popular se muestra el interés de los habitantes de un lugar acerca de las políticas ambientales. Con la denuncia popular, la sociedad en su conjunto puede evidenciar los excesos y delitos que están cometiendo al ambiente, tanto particulares como el propio Estado.

Cuando hablamos de acceso a la justicia, es básico que las personas cuenten con una herramienta para defender el ambiente. Esto es una referencia directa del principio 10 de la Declaración de Río, que consagra el derecho humano a la justicia en materia de protección ambiental y reparación del daño: “...Deberá proporcionarse acceso efectivo a los procedimientos judiciales y administrativos, entre éstos el resarcimiento de daños y los recursos pertinentes".

$\mathrm{Al}$ respecto, el ACAAN establece "la importancia de la participación de la sociedad en la conservación, la protección y el mejoramiento del medio ambiente y contempla como metas de las Partes, entre otras, lograr niveles altos de protección del ambiente y de cumplimiento de las leyes de las Partes". ${ }^{20}$ A su vez, el mismo acuerdo obliga a México informar a la Comisión sobre el estado del ambiente y la promoción de la participación pública.

\section{La denuncia popular en el derecho interno}

La denuncia popular se encuentra regulada en el artículo 189 de la Ley General del Equilibrio Ecológico y la Protección al Ambiente. Establece como derecho de "toda persona, grupos sociales, organizaciones no gubernamentales, asociaciones y sociedades" el poder denunciar ante la Profepa y otras autoridades "todo hecho, acto u omisión que produzca o pueda producir desequilibrio ecológico o daños al ambiente o a los recursos naturales".

Bajo esta lógica de responsabilidad compartida entre el Estado y la sociedad, ${ }^{21}$ y en la que el primero proporciona los instrumentos y proce-

20 Expediente de hechos, p. 21.

21 Como bien ha señalado Raúl Brañes, "El deber del Estado y de la sociedad de proteger el medio ambiente es cronológicamente, el primero de los principios que aparece en

Esta obra está bajo una Licencia Creative Commons

Atribución-NoComercial-SinDerivar 4.0 Internacional, IIJ-UNAM.

Boletín Mexicano de Derecho Comparado, núm. 151, pp. 85-106. 
dimientos necesarios para que la sociedad pueda satisfacer su derecho de acceso a la justicia. Los habitantes de la sierra tarahumara, utilizando los instrumentos jurídicos a su alcance, interpusieron casi treinta denuncias populares, en las que daban aviso a las autoridades correspondientes de actividades de tala ilegal y extracción de recursos en su territorio. ${ }^{22}$

Entre los años de 1998 y 1999, tres comunidades indígenas de la sierra tarahumara: Ciénega de Guacayvo, Rochéachi y Pino Gordo, presentaron 28 denuncias populares; todas forman parte del expediente hechos que presentó el Secretariado de la CGA. En ellas se denunciaba tala ilegal e incendios provocados en sus bosques.

Con asistencia de la Comisión de Solidaridad y Defensa de los Derechos Humanos, A. C. (Cosyddac), el 31 de mayo de 2000 esas tres comunidades presentaron al Secretariado "una petición en la que asevera que México está incurriendo en omisiones en la aplicación efectiva de su legislación ambiental respecto del trámite de denuncias populares y la persecución de probables delitos ambientales en relación con la tala ilegal y otras actividades de extracción de recursos". ${ }^{23}$

Dicho lo anterior, hemos entendido que el instrumento utilizado para acceder a la justicia por las comunidades fue la denuncia popular. Así que después de ver por qué y qué es esta figura, es necesario entender cómo se le da seguimiento, así como sus etapas. Para referencia se puede ver el cuadro 1, en el que explicamos sus etapas y qué puede suceder en cada una de ellas, conforme a los artículos 189 a 204 de la LGEEPA.

las nuevas Constituciones latinoamericanas". Implica reconocer el carácter constitucional de la protección al medio ambiente y la obligación del Estado a ella. En Brañes, Raúl, $M a-$ nual de derecho ambiental mexicano, 2a., ed., México, Fundación Mexicana para la Educación Ambiental-Fondo de Cultura Económica, 2000, p. 100.

22 Para conocer sobre los instrumentos de participación para la sociedad, se puede consultar Anglés Hernández, Marisol, "Denuncia popular, ¿ejercicio de la participación pública en la protección ambiental?", Lex-Difusión y Análisis, México, año IX, tercera época, núm. 120, junio de 2005.

23 Expediente de hechos, p. 7. 


\section{Denuncia popular}

\section{Requisitos para denunciar}
$\vdots$
I. El nombre o razón social, domicilio y teléfono del denunciante y, en su caso, de su representante legal;
II. Los actos, hechos u omisiones denunciados;
III. Los datos que permitan identificar al presunto infractor o la fuente contaminante, y
IV. Las pruebas, en caso de existir.

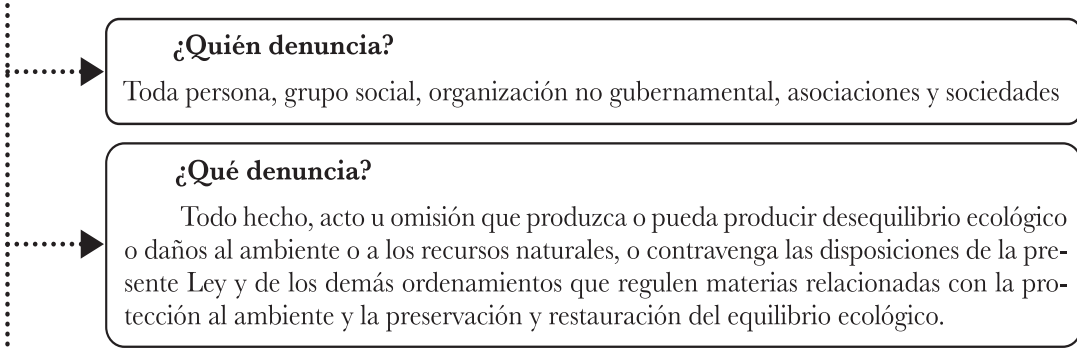

\section{Procedimiento}
A) Recepción de la denuncia popular por escrito, a través del módulo de atención ciu- dadana o de manera personal, o vía telefónica que se ratificará a los tres días si- guientes.
B) Profepa acusa de recibo la recepción de la denuncia y asigna un número de expe diente y registro.
C) Profepa admite la instancia.
D) En caso de recibir dos o más denuncias, se acuerda la acumulación y se notifica.
E) Profepa queda obligada a informar al denunciante en el término de diez días sobre el trámite que le ha dado a la denuncia.

\section{Resolución}
A) Recomendación (artículo 195 de la LEGEEPA).
B) Procedimiento de conciliación (artículo 196 de la LEGEEPA).
C) Se determina que no se comprueban los hechos (artículo 197 de la LEGEEPA).
D) Resuelve formular denuncia ante M.P.F. (artículo 182 de la LEGEEPA).
E) Inicia procedimiento de inspección (última parte del artículo 192 de la LEGEEPA)

\section{Conclusión de un expediente}

A) Por incompetencia de la Procuraduría Federal de Protección al Ambiente para co nocer de la denuncia popular planteada;

B) Por haberse dictado la recomendación correspondiente;

C) Cuando no existan contravenciones a la normatividad ambiental;

D) Por falta de interés del denunciante en los términos de este capítulo;

E) Por haberse dictado anteriormente un acuerdo de acumulación de expedientes;

F) Por haberse solucionado la denuncia popular mediante conciliación entre las partes;

G) Por la emisión de una resolución derivada del procedimiento de inspección, o

$\mathrm{H})$ Por desistimiento del denunciante.

Esta obra está bajo una Licencia Creative Commons

Atribución-NoComercial-SinDerivar 4.0 Internacional, IIJ-UNAM.

Boletín Mexicano de Derecho Comparado, núm. 151, pp. 85-106. 
Hará del conocimiento la denuncia a la persona o personas, o a las autoridades a quienes se imputen los hechos denunciados o a quienes pueda afectar el resultado de la acción emprendida, a fin de que presenten los documentos y pruebas que a su derecho convenga en un plazo máximo de quince días hábiles, a partir de la notificación respectiva

Las tres comunidades indígenas presentaron un total de 28 denuncias populares, de las cuales sólo diecisiete dieron lugar al inicio de procedimiento administrativo por parte de la Profepa; en dieciséis, la dependencia ordenó sanciones con multas o medidas correctivas, y sólo en nueve de esos casos se instrumentaron algunas de las medidas.

Sin embargo, en ninguno de los casos se cumplió con la reforestación impuesta como medida correctiva. De hecho, uno de los resultados inesperados de las denuncias fue que al ejido denunciante se le ordenó realizar actividades de reforestación, "toda vez que las autoridades gubernamentales consideraron que el ejido era responsable de haber permitido que la tala ilegal se realizara".

Diferencias culturales, comunidades alejadas de centros urbanos, pero sobre todo un procedimiento administrativo poco efectivo, han ocasionado que en la sierra tarahumara la justicia ambiental no tenga efectividad; aunque en la teoría se reconoce que la denuncia popular es el instrumento para que habitantes y autoridades colaboren responsablemente sobre la protección del ambiente, en este caso resulta ser un instrumento deficiente. El expediente de hechos resume los resultados que obtuvieron las comunidades con el proceso de la denuncia popular en el siguiente párrafo:

De las 32 denuncias populares (o 28 considerando las acumuladas como un solo caso), 20 fueron admitidas en un periodo que excedió los diez días establecidos; cinco fueron total o parcialmente turnadas a otra dependencia, y siete fueron rechazadas por la Profepa. En 17 casos las denuncias dieron lugar al inicio de procedimientos administrativos, de los cuales 16 resultaron en órdenes de sanción con multas o medidas correctivas. En nueve de esos casos se instrumentaron algunas o todas las medidas correctivas. Si bien en nueve casos se ordenó la reforestación, ésta se realizó sólo en tres, pero nunca por los infractores, sino por el propio ejido. Con respecto de los casos en que se impusieron multas, el Secretariado no recibió información alguna acerca de su recaudación. ${ }^{24}$

24 Expediente de hechos, pp. 50 y 51.

Esta obra está bajo una Licencia Creative Commons Atribución-NoComercial-SinDerivar 4.0 Internacional, IIJ-UNAM. Boletín Mexicano de Derecho Comparado, núm. 151, pp. 85-106. 
¿Cuántas denuncias populares se requieren para evitar los daños ambientales? En la sierra tarahumara quedó claro que deben ser más de treinta, ya que con el número de denuncias presentadas no se logró poner un alto a las actividades que degradan los bosques de la región.

En términos generales, el Estado mexicano usa como argumento la poca infraestructura y falta de personal de la Profepa; sin embargo, con la lectura del expediente de hechos se puede deducir que tampoco busca el respaldo de otras instituciones, como el Ministerio Público federal (MPF).

Inclusive en una de las respuestas del gobierno mexicano a la Comisión, informa que cinco de los casos no fueron presentados ante el MPF, argumentando el "principio de mínima intervención”, que consiste en no presentar asuntos que se consideran de poca importancia. Claro que ésta es una decisión discrecional de la autoridad, y valora con los datos que se pueden tener en un escritorio.

Del asunto analizado surge la siguiente pregunta: ¿la denuncia popular es el instrumento más adecuado para garantizar el acceso a la justicia ambiental? A la luz de los hechos de este caso, la respuesta es no. Con comunidades alejadas, una comunicación complicada con los centros urbanos y las oficinas de las autoridades, se dificulta físicamente el acceso, y que las autoridades garanticen la protección a su derecho humano a un ambiente sano.

Además, se suma la diferencia cultural que conllevan denuncias presentadas por pueblos indígenas, rarámuris y tepehua, que va desde la concepción del bosque hasta la lengua para comunicarse.

Sin lugar a dudas, la denuncia popular es un instrumento para que las personas puedan acceder a la justicia ambiental; pero cuando éstas no ven resultados concretos, y sobre todo no ven resueltos los hechos que deterioran el ambiente - ejemplo el presente caso-, este instrumento se vuelve ineficaz, e incluso puede ser un obstáculo para la gobernanza. ${ }^{25}$

25 Señala César Rodríguez Garavito que la gobernanza no es la regulación impuesta por el Estado, "ni la autorregulación de los mercados, sino una «tercera vía», consistente en regulaciones flexibles producidas mediante la deliberación y la cooperación entre los actores afectados por ellas, que van desde las empresas y las entidades estatales hasta las comunidades de base, pasando por las ONG, los sindicatos y las asociaciones ciudadanas". En Rodríguez Garavito, César, Etnicidad.gov Los recursos naturales, los pueblos indigenas y el derecho a la consulta previa en los campos sociales minados, Bogotá, Centro de Estudios de Derecho, Justicia y Sociedad, Dejusticia, 2012, p. 31. 
¿Cuál sería la propuesta?, ¿cómo se puede lograr que la participación de la sociedad fortalezca la gobernanza, garantice el cuidado de los recursos naturales, y sobre todo desincentive las actividades ilegales que los degradan?

Existen propuestas que señalan que para acabar con la tala ilegal y optimizar los recursos humanos y económicos de la Profepa es necesario que ésta cuente con facultades de inspección y vigilancia en puntos de venta de madera, como pueden ser madererías, grandes carpinterías, e incluso mueblerías; esto limitaría el acceso de la madera ilegal al mercado.

Otra de las propuestas que se han presentado entre los actores del sector forestal, es la creación de grupos de vigilancia comunitarios, mediante programas de participación comunitaria y educación forestal. Al respecto, la Comisión Nacional Forestal (Conafor) tiene programas de capacitación, e incluso tiene asignados recursos para el equipamiento de los grupos, ya sea con equipos de comunicación, uniformes o capacitación. Los resultados particularmente se han observado en el mejor manejo del fuego y en la atención oportuna de plagas. ${ }^{26}$

Implementar este tipo de políticas contribuye a cumplir con disposiciones del Convenio 169 sobre Pueblos Indígenas y Tribales en Países Independientes, depositado por México ante el director general de la Organización Internacional del Trabajo en 1990, y también dar cumplimiento al artículo segundo constitucional, ya que crea condiciones para lograr el ejercicio de la autodeterminación de los pueblos indígenas y su inclusión al Estado democrático.

\section{MÉXICO Y EL EXPEDIENTE DE HECHOS FINAL}

La Comisión para la Cooperación Ambiental concluye de manera categórica que "México ha incurrido en omisiones en la aplicación efectiva de su legislación ambiental por la denegación de justicia ambiental a pueblos indígenas en la Sierra Tarahumara, en el Estado de Chihuahua".

Podría pensarse que una frase de tal contundencia será relevante para cambiar la legislación o los procesos de las instituciones; sin embargo, la nota final del expediente de hechos explica cuál será el alcance de éste.

26 Comisión Nacional Forestal, Capacitación Empresarial Forestal, disponible en: http:// wrwe.conafor.gob. $m x /$ cenefor/index.php?page $=$ contenido Eid $=4$.

Esta obra está bajo una Licencia Creative Commons Atribución-NoComercial-SinDerivar 4.0 Internacional, IIJ-UNAM. Boletín Mexicano de Derecho Comparado, núm. 151, pp. 85-106. 
Su utilidad se limita a proporcionar información sobre presuntas omisiones en la aplicación efectiva de la legislación ambiental de alguno de los países firmantes, con el fin de que la información recopilada y el pronunciamiento sirva de apoyo a los peticionarios, a las partes del ACAAN y a cualquier persona que considere o pueda emprender alguna acción relacionada con el caso expuesto.

La Resolución del Consejo 03-04, [el] expediente de hechos proporciona información relevante para considerar si México está incurriendo en omisiones en la aplicación efectiva de su legislación ambiental respecto al trámite de 28 denuncias populares que comunidades indígenas de la Sierra Tarahumara, estado de Chihuahua, presentaron ante autoridades federales entre 1998 y 2000 por presuntas actividades de tala ilegal y extracción de recursos naturales, y la interposición de sanciones penales en relación con tales actividades. ${ }^{27}$

De igual forma, la nota final esclarece que las autoridades admitieron las denuncias populares en plazos que superaron el periodo que la LGEEPA establece, y cerraron los expedientes en plazos posteriores a los tiempos establecidos por la misma ley.

El mismo expediente de hechos final se manifestó en la falta de información brindada por el Estado mexicano al Secretariado conforme a los dieciséis casos en donde las denuncias populares daban lugar a la autoridad mexicana a ordenar las medidas necesarias para su cumplimiento, así como su posible sanción penal.

Derivado de ello, las autoridades mexicanas, en los casos que ellas discrecionalmente consideraron que los hechos no eran elementos constitutivos de algún delito ambiental, proporcionaron las razones que fundamentan y motivan sus decisiones al Secretariado.

Asimismo, los desafíos para la aplicación efectiva de la legislación ambiental fueron identificados en las relaciones entre comunidades indígenas y autoridades dentro de su cooperación intergubernamental - relación entre los tres niveles de gobierno y su mal distribución de recursos económicos-e interinstitucional.

Entre dichos desafíos, el expediente de hechos establece a la ubicación geográfica de las comunidades, en la sierra tarahumara, como una razón

27 Expediente de hechos.

Esta obra está bajo una Licencia Creative Commons

Atribución-NoComercial-SinDerivar 4.0 Internacional, IIJ-UNAM.

Boletín Mexicano de Derecho Comparado, núm. 151, pp. 85-106. 
de los tiempos de traslado para que las autoridades realicen las inspecciones necesarias en la investigación de las denuncias.

A su vez, las diferencias lingüísticas se manifestaron como barreras para la comunicación y el acceso a los habitantes de las comunidades. Pero, sobre todo, contar con inspectores suficientes, calificados y bien remunerados, para dar un buen seguimiento a los asuntos objeto de las denuncias populares. Éstos constituyen los grandes desafíos a la aplicación efectiva de la legislación ambiental, y, por tanto, de la exigibilidad de la justicia ambiental.

Para la creación del expediente de hechos final, el Estado mexicano, con fundamento en el artículo 15 (5) del ACAAN, presentó sus comentarios a la Comisión, y se manifestó considerando:

Primero. Que "La violación a los Derechos Humanos no es objeto de Petición Ciudadana en el contexto de los artículos 14 y 15 del ACAAN, sino la legislación ambiental", por lo que consideró que el proyecto de expediente de hechos final iba más allá del objeto del acuerdo.

Segundo. Consideró que la situación de los Derechos Humanos y las Libertades Fundamentales de los indígenas eran temas no ambientales, de conformidad con el artículo 45(2). ${ }^{28}$

De una correcta revisión e interpretación del artículo 45 (2), no se desprende fundamento alguno para que el Estado mexicano considerara que el objeto del expediente de hechos iba más allá de la materia ambiental; a saber: el precepto normativo 45(2) simplemente se encarga de dar la definición de lo que es "legislación ambiental" para el acuerdo, y no detalla excepción alguna que México pueda hacer válida.

Por último, cabe señalar que la respuesta de México es errónea, pues es claro que la materia ambiental es de carácter holístico, y, por ende, tiene implicaciones en diversos sectores; es allí donde reside su carácter transectorial.

28 Precisa el artículo 45 las definiciones para efectos de la ley, y en su apartado segundo establece: "legislación ambiental" significa cualquier ley o reglamento de una parte, o sus disposiciones, cuyo propósito principal sea la protección del medio ambiente, o la prevención de un peligro contra la vida o la salud humana". Véase en Acuerdo de Cooperacion Ambiental de América del Norte. 


\section{CONSIDERAGIONES FINALES}

En la nota final del expediente hay una frase que resalta por su contundencia, y que se refiere a uno de los grandes problemas del país: "la falta de seguimiento gubernamental a los asuntos objeto de las denuncias populares afecta la percepción sobre la efectividad del proceso de la denuncia popular".

La inefectividad de instrumentos como la denuncia popular refleja el carácter sistémico de la impunidad en nuestro país; $;{ }^{29}$ esto provoca que los gobernados no crean en sus autoridades, ocasionando una falta de gobernabilidad y una negación de la justicia, y que los esfuerzos en los que se pretenden involucrar a las personas no rindan frutos, e incluso la relación con las autoridades se vea debilitada.

Además, el hecho de que la denuncia popular sea un mecanismo de carácter administrativo, que sólo puede resultar en recomendaciones administrativas, procedimientos de conciliación, denuncias ante el Ministerio Público Federal para que éste inicie un procedimiento de inspección, impide satisfacer las expectativas de quienes denuncian, ya que se espera una sanción sobre los infractores, hecho que es imposible, debido a la naturaleza jurídica del mecanismo.

Sobre la CCA y su atribución de formar expedientes de hechos y hacerlos públicos, claramente es una figura que no pretende obligar a los países para que cumplan con su legislación ambiental, por lo que no se puede decir que sea el instrumento que va a garantizar que las personas vivamos en un ambiente sano; pero es mejor que exista la figura y que haya una autoridad externa a cada una de las partes del ACAAN que esté observando si los países cumplen con su normatividad ambiental, generando una opinión pública.

Las políticas para atacar el problema de la tala ilegal tradicionalmente se han centrado en detener y sancionar a las personas que derriban los árboles o los transportan. La Procuraduría Federal de Protección al Ambiente centra sus esfuerzos con inspecciones en los bosques y en los caminos. Los resultados de esta política no tienen el impacto que se necesita para el nivel del problema.

29 Aristegui Noticias, "La impunidad que vive el país es sistémica y endémica", Así ven a México: 4 informes sobre el país, en http://aristeguinoticias. com/2006/mexico/asi-ven-a-mexico4-informes-sobre-el-pais/?utm_source $=$ feedburnerËutm_medium $=$ emailËutm_campaign $=$ Feed $\% 3 \mathrm{~A}+$ AristeguiNoticias+\%28Aristegui + Noticias\%29 (consultado el 23 de junio).

Esta obra está bajo una Licencia Creative Commons

Atribución-NoComercial-SinDerivar 4.0 Internacional, IIJ-UNAM.

Boletín Mexicano de Derecho Comparado, núm. 151, pp. 85-106. 
Continuar con esa política seguirá poniendo en riesgo la vida del personal de las instituciones, y no basta con detener o sancionar a quien corta los árboles, sino que es necesario saber qué se hace con esa madera, a quién se le vende, qué productos se obtienen de esos árboles y en dónde se comercializa; es necesario rastrear la madera ilegal en todo el proceso de la cadena de valor, para poder diseñar estrategias que realmente acaban con uno de los problemas que causan alrededor del 8\% de la deforestación del país. ${ }^{30}$

El expediente de hechos de este caso refleja que la denuncia popular no es el instrumento jurídico que garantice el acceso a la justicia y permita a la sociedad involucrarse adecuadamente en el cuidado del ambiente y la coordinación con la autoridades, sobre todo porque la capacidad técnica y humana de las instituciones está rebasada, e incluso no pueden cumplir con los plazos legales, como se comprobó en el expediente en referencia.

Hoy en día, el acceso a la justicia ambiental es de suma importancia para las personas y el gobierno, pues mediante ella se garantiza la procuración, protección y restauración del medio ambiente, y en la gran mayoría de los casos contribuye a la realización del derecho humano a un ambiente sano para la población. De tal suerte, es necesario que el gobierno mexicano respete la ley ambiental y realice todo tipo de combate contra la impunidad, para que así, de esta manera se reviertan los procesos de deterioro ambiental y se prevengan futuros actos que dañen al medio ambiente.

Por lo anterior, se advierte que la Profepa, institución encargada de vigilar a nivel federal el cumplimiento de las leyes ambientales derivadas de la Constitución y los tratados internacionales celebrados por México, deja en cierto grado de incertidumbre e inseguridad jurídica a las y los mexicanos. De tal suerte que no se está garantizando un correcto acceso a la justicia ambiental.

El hecho de que la autoridad, Profepa, espere que el particular aporte pruebas, e incluso que indique datos que permitan identificar al presunto infractor, transfiere su responsabilidad, particularmente, en el caso específico de la tala de árboles, al ser clandestino, es ejecutado por personas enviadas por un autor intelectual, que muchas veces no es identificado, y el

30 Comisión Nacional Forestal, Propuesta de actualización programa estratégico forestal para México 2025, p. 36, disponible en: http://wrewe.conafor.gob.mx/portal/index.php/acerca-de-conafor /programa-estrategico-forestal-2025 (consultado el 20 de junio de 2014).

Esta obra está bajo una Licencia Creative Commons Atribución-NoComercial-SinDerivar 4.0 Internacional, IIJ-UNAM. Boletín Mexicano de Derecho Comparado, núm. 151, pp. 85-106. 
particular no tiene las facultades jurídicas ni los recursos para averiguarlo; sin duda es un ejemplo de cómo la autoridad impide el acceso a la justicia de los gobernados.

Otro tema a revisar, sobre la efectividad de la denuncia popular, es que al no ejercer de manera inmediata la inspección administrativa, puede transcurrir mucho tiempo antes de resolver la situación planteada en la denuncia popular.

Al final, el tema que nos ocupa no tuvo tanta trascendencia en la opinión pública, ya que del estudio hemerográfico sólo hemos encontrado dos notas sobre este caso: una en el semanario Proceso $^{31}$ y otra en el diario La fornada, ${ }^{32}$ ambos de circulación nacional.

Sin embargo, para que un expediente de hechos tenga consecuencias positivas necesita contar con un fuerte impacto en los medios de comunicación; si no, se limita a ser un documento que puede ser utilizado por los promoventes del caso y algunas organizaciones sociales interesadas en el tema.

Respecto a la CCA y al expediente de hechos, su trascendencia e impacto en las instituciones nacionales dependerá de la capacidad que tengan los promoventes para que el caso trascienda en la agenda pública si no logran captar los reflectores de la prensa y respaldarse de un amplio grupo de organizaciones que retomen el tema y exijan que se atiendan las recomendaciones.

\section{BIBLIOGRAFÍA}

AGuerdo de CoOperación Ambiental de AmériCa Del NorTe, disponible en: http://wrer.cec.org/Page.asp?PageID=1226E'SiteNodeID =567 EAA_SiteLanguageID=3, fecha de consulta 27de junio de 2014.

AnglÉs Hernández, Marisol, "Denuncia popular, ¿ejercicio de la participación pública en la protección ambiental?", Lex-Difusión y Análisis, México, año IX, tercera época, núm. 120, junio de 2005.

Anglés Hernández, Marisol, La protección ambiental en México a través de la denuncia popular, consultado el 10 de junio en: http://wrere.ambito-juridico. com.br/site/index.php?n_link=revista_artigos_leituraEartigo_id $=170$.

31 Revista Proceso, disponible en: http://wrere.proceso.com.mx/:p=213692.

32 Diario La Fornada, disponible en: http://wrere.jornada.unam.mx/archivo_opinion/index. php/autor/front/96/11259.

Esta obra está bajo una Licencia Creative Commons

Atribución-NoComercial-SinDerivar 4.0 Internacional, IIJ-UNAM.

Boletín Mexicano de Derecho Comparado, núm. 151, pp. 85-106. 
BRAÑes, Raúl, Manual de derecho ambiental mexicano, 2a. ed., México, Fundación Mexicana para la Educación Ambiental-Fondo de Cultura Económica, 2000.

Carmona Lara, María del Carmen, "El Tratado de Libre Comercio y el ambiente (acuerdos paralelos)", en WITKER, Jorge (coord.), El Tratado de Libre Comercio de América del Norte. Análisis, diagnóstico y propuestas jurídicas, México, UNAM, Instituto de Investigaciones Jurídicas, 1993, t. II.

COMisión NAGiOnal FOREstal, Propuesta de actualización programa estratégico forestal para México 2025, disponible en: http://wwrw.conafor.gob.mx/ portal/index.php/acerca-de-conafor/programa-estrategico-forestal-2025, consultado el 20 de junio de 2014.

Expediente de Hechos Final, Petición Ciudadana Tarahumara (SEM00-006), disponible en: http://wrww3.cec.org/islandora/en/item/2750-north-american-environmental-law-and-policy-volume-20-es.pdf.

Gros EsPiELL, Héctor, "El derecho al desarrollo como un derecho de la persona humana", Revista de Estudios Internacionales, Madrid, Centro de Estudios Constitucionales, vol. I, núm. 1, enero-marzo de 1980.

Herrera Flores, Joaquín, La reinvención de los derechos humanos, Andalucía, Atrapasueños, 2008.

Herrera Torres, Sergio Eduardo, "Acceso a la justicia ambiental", en Carmona Lara, María del Carmen et al., 20 años de procuración de justicia ambiental en México. Un homenaje a la creación de la Procuraduría Federal de Protección al Ambiente, México, UNAM, Instituto de Investigaciones Jurídicas, 2012.

NAVA Escudero, César, Estudios ambientales, 2a. ed., México, UNAM, Instituto de Investigaciones Jurídicas, 2011.

PISARELlO, Gerardo, Los derechos sociales y sus garantías. Elementos para una reconstrucción, Madrid, Trotta, 2007.

Ponce NAVA, Diana Lucero, "Procuración y acceso a la justicia ambiental y territorial en México", en ORdóÑEz Cifuentes, José Emilio Rolando y Anglés Hernández, Marisol, Primera Memoria del Seminario Itinerante Internacional "La cuestión agraria: tierras, territorios, medio ambiente, recursos naturales, migrantes, derechos sociales y colectivos de los pueblos", México, UNAM, Instituto de Investigaciones Jurídicas, 2012.

Rodríguez GARAVITO, César, Etnicidad.gov Los recursos naturales, los pueblos indigenas y el derecho a la consulta previa en los campos sociales minados, Bogotá, Centro de Estudios de Derecho, Justicia y Sociedad, Dejusticia, 2012. 
Esta revista forma parte del acervo de la Biblioteca Jurídica Virtual del Instituto de Investigaciones Jurídicas de la UNAM

STUDER, Isabel, Comercio, medio ambiente y asuntos laborales. Hacia un modelo de cooperación en America del Norte, disponible en: biblio.juridicas.unam.mx/ libros/6/2904/13.pdf, consultado el 25 de junio de 2014

VASAK, Karel, "La larga lucha por los derechos humanos", El Correo de la UNESCO, noviembre de 1977.

Witker Velásquez, Jorge Alberto, Derecho del comercio exterior, México, UNAM, Instituto de Investigaciones Jurídicas-Asociación de Agentes Aduanales del Aeropuerto de México, A. C., 2011. 